\title{
Editorial
}

\section{Editorial on the Citizen Science and Geospatial Capacity Building}

\author{
Sultan Kocaman ${ }^{1, *} \mathbb{0}$, Sameer Saran ${ }^{2}$, Murat Durmaz ${ }^{1}\left(\mathbb{D}\right.$ and Senthil Kumar ${ }^{3}$ \\ 1 Department of Geomatics Engineering, Hacettepe University, Ankara 06800, Turkey; \\ muratdurmaz@hacettepe.edu.tr \\ 2 Indian Institute of Remote Sensing, Indian Space Research Organisation, 4 Kalidas Road, \\ Dehradun 248001, India; sameer@iirs.gov.in \\ 3 ISPRS TC-V President, Former Director Indian Institute of Remote Sensing (ISRO), Dehradun 248001, India; \\ senthil.iirs@outlook.com \\ * Correspondence: sultankocaman@hacettepe.edu.tr
}

check for updates

Citation: Kocaman, S.; Saran, S.; Durmaz, M.; Kumar, S. Editorial on the Citizen Science and Geospatial Capacity Building. ISPRS Int. J. Geo-Inf. 2021, 10, 741

https://doi.org/10.3390/ijgi10110741

Received: 21 October 2021

Accepted: 23 October 2021

Published: 1 November 2021

Publisher's Note: MDPI stays neutra with regard to jurisdictional claims in published maps and institutional affiliations.

Copyright: (C) 2021 by the authors Licensee MDPI, Basel, Switzerland. This article is an open access article distributed under the terms and conditions of the Creative Commons Attribution (CC BY) license (https:// creativecommons.org/licenses/by/ $4.0 /)$
Abstract: This article introduces the Special Issue on "Citizen Science and Geospatial Capacity Building" and briefly evaluates the future trends in this field. This Special Issue was initiated for emphasizing the importance of citizen science (CitSci) and volunteered geographic information (VGI) in various stages of geodata collection, processing, analysis and visualization; and for demonstrating the capabilities and advantages of both approaches. The topic falls well within the main focus areas of ISPRS Commission V on Education and Outreach. The articles collected in the issue have shown the enormously wide application fields of geospatial technologies, and the need of CitSci and VGI support for efficient information extraction and synthesizing. They also pointed out various problems encountered during these processes. The needs and future research directions in this subject can broadly be categorized as; (a) data quality issues especially in the light of big data; (b) ontology studies for geospatial data suited for diverse user backgrounds, data integration, and sharing; (c) development of machine learning and artificial intelligence based online tools for pattern recognition and object identification using existing repositories of CitSci and VGI projects; and (d) open science and open data practices for increasing the efficiency, decreasing the redundancy, and acknowledgement of all stakeholders.

Keywords: geospatial capacity building; citizen science; volunteered geographic information; crowdsourcing; participatory GIS

\section{Introduction}

Citizen science and volunteered geographic information (VGI) are gaining importance with the ubiquitous use of mobile technologies. In this new era, ordinary citizens may contribute to scientific processes based on their interest and abilities. The activities they may contribute to range from biology to environmental monitoring to classification of galaxies, all of which have a spatiotemporal dimension. The increasing demands on this research agenda are encouraging scientists from diverse backgrounds to collaborate under the term of "Citizen Science (CitSci)". Geospatial tools and technologies enable many CitSci projects and also benefit from them. Geospatial capacity building, which is one of the main focus areas of ISPRS Commission V on Education and Outreach, also benefits from these developments.

The Special Issue on "Citizen Science and Geospatial Capacity Building" aimed at emphasizing the increasing importance of CitSci, open science and open data in the scientific world for capacity building. The research articles collected in the Special Issue on "Citizen Science and Geospatial Capacity Building" demonstrated the increased efforts on the capacity building by researchers and citizen scientists; and outlined the significance of data quality in various projects, the possibilities provided by web and mobile geographic 
information system (GIS) technologies, web-based sharing of resources, the role of social media and crowdsourcing data collection methods, and semantical issues. The published articles are briefly introduced in the next Section. The main contributions of the Special Issue are summarized in the final section, and the future directions derived therefrom are presented.

\section{Contributions of the Special Issue}

The study by Singh et al. [1] presented a novel approach for the prediction of future habitats for monitoring of a bird species, the Jacobin cuckoo (Clamator jacobinus), using a combination of spatial modeling and machine learning (ML) techniques, i.e., the maximum entropy (Maxent) algorithm. The predictions were carried out for the years 2030 and 2050 under various future global climate modeling approaches using the Coupled Model Intercomparison Project (CMIP5)'s climate data of the CNRM-ESM2-1 [2]. An extensive review on the use of CitSci for biodiversity research was provided in the study. The study demonstrated the usability and essentiality of CitSci collected geodata for this kind of global analysis, which cannot be carried out by using institutional observations solely. The species distribution data was obtained from the Global Biodiversity Information Facility (GBIF) repository [3].

In a similar context, Zhang [4] analyzed the spatial sampling pattern of eBird (www.ebird.org (accessed on 15 October 2021)) data for analyzing the geographical and temporal distributions of the participants using the Maxent algorithm. The study revealed various types of biases (i.e., spatial, temporal, contributor and observation) in the collected data. The outcomes of the study indicated that the volunteers' efforts are uncoordinated, concentrated in highly accessible areas, which yield to hotspots with poor geographical coverage and in specific time periods, such as weekends. The diversity in the backgrounds (e.g., expert birders are more interested in rare species) and the contribution frequency of the volunteers also cause biases in the eBird database. The study emphasized that such bias patterns should be taken into account when performing analyses and deriving conclusions from VGI data.

Samulowska et al. [5] addressed the data bias in VGI and developed a geospatial web platform with a robust quality assurance (QA) approach. The article includes an extensive literature review on the CitSci contribution for air pollution mapping. The authors proposed a validation method for the detection and removal of bias in CitSci collected data by using a logical workflow and rules specifically designed for air pollution assessment. They concluded that the citizens can provide reliable data together with scientists, and can contribute to the QA process as well. On the other hand, the motivating mechanisms for participation require further research.

Gulnerman et al. [6] also analyzed the anomaly and the bias in VGI obtained from a social network service (SNS), i.e., Twitter, by using the data from Istanbul, Turkey. The data was obtained from approximately $80 \mathrm{k}$ users with a total amount of 4 million tweets. They focused on the spatiotemporal patterns of the data in a $1 \mathrm{~km} \times 1 \mathrm{~km}$ grid. With their proposed statistical approach, it was possible to detect anomalies and biases and replace with the expected values. The study revealed several outcomes such as; highly active users produce the majority of the data; the anomaly patterns may vary and the normalization approach should be defined accordingly; the anomaly pattern is stronger in dense population areas; and the biases also exhibited different temporal patterns.

Gray et al. [7] developed an open source tool named Community Water Data Analysis Tool (CWDAT) for water quality monitoring. In the system design, they co-created with the citizen scientists and put special emphasis on the data quality assessment and user engagement. By developing and providing the tool as open source, they also contributed to geospatial capacity building. A major outcome of the study was that the engagement of volunteers in the design stage facilitates the participation and contributes to the citizen perception of data quality, which is a significant issue, as stated in many other CitSci 
projects. The authors also emphasized the importance of presentation (e.g., visualization) and availability of proper guidelines for an increased success.

Yalcin et al. [8] developed a mobile app ("I felt the quake") to aid emergency management after earthquakes and to support earthquake-related studies by providing timely and spatially accurate data. The study includes an extensive review on the use of CitSci in earthquake related hazards and the availability of similar CitSci apps. The proposed app utilizes a modified version of the Mercalli scale, a scientific standard to assess the earthquake intensity. The scale was modified by [8] for increasing its usability and understandability by non-professionals. The volunteers were also trained by giving specific guidelines. In the experimental application, it was proven that the CitSci data quality can be as high as those provided by professionals when appropriate tools and guidelines are provided.

Vahidnia and Vahidi [9] analyzed the spatial data infrastructure (SDI) aspect of geoportals with a focus on public participation, and proposed a model called "Open CommunityBased Crowdsourcing Geoportal for Earth Observation Products" (OCCGEOP) particularly for Earth Observation (EO) data. The framework considered the well-known spatial data structures and methodological standards from Open Geospatial Consortium (OGC), quality control and engagement mechanisms, facilitating the communication between users for improved interaction and sharing, data search and discovery and relying on open source technologies. The authors emphasized the importance of ontology to resolve or to reduce the semantic heterogeneity and to contribute to semantic interoperability; and pointed out these issues as future work. Integration of existing SNS and overcoming the language barriers were also mentioned for the same purpose.

Perdana and Ostermann [10] analyzed the background of participatory toponym handling and addressed several issues on the use of CitSci for leveraging the knowledge in this field in collaboration with governments. In the study, a generic framework was proposed for toponym handling and modified for Indonesia by utilizing collaborative learning among multiple stakeholders. The study emphasized the importance of open science and showed the applicability of the generic framework locally for concrete cases. An important outcome of the study was the acceptance of CitSci by national government in the legal framework. The authors stated that the different user perspectives and backgrounds as well as the motivations remained among the key issues in participatory approaches.

\section{Summary and Future Directions}

The scientific contributions and lessons-learned from the articles published in the Special Issue can be summarized as following;

- The CitSci and VGI are highly valuable for geospatial capacity building and for facilitating scientific developments.

- Open science and open data are key for multi-stakeholder (e.g., citizens, local and national governments, multinational organizations) collaboration.

- The citizen scientists have diverse backgrounds, and co-creation activities help to overcome issues sourced from this diversity.

- Although the data quality remains among major challenges, several approaches such as statistical, logical, spatial analysis, machine learning (ML), and collaborative methods can be utilized for this purpose.

- Revealing the spatial, social and temporal patterns in the CitSci collected data also supports reliable knowledge extraction and increasing the data quality.

- The geospatial application fields of CitSci and VGI are diverse and can benefit from each other for efficient implementation and analysis of such projects.

- Ontological studies are essential for developing scalable frameworks and increasing the participation capability, interoperability, and building the necessary capacity at various levels (e.g., local, regional, national, etc.).

- Platform integration efforts, i.e., between SNS and specifically developed CitSci environments, can also improve the success of such studies. 
Based on the lessons learned and the recent developments in geospatial technologies, the concrete proposals and future directions derived from the views of the Guest Editors can be listed as:

- Considering the advancements in communication infrastructures and increased accessibility to the mobile computing devices such as cellular phones, the amount of data collected by individuals in the form of digital photos have been boosted, in addition to digital sound and sensor data such as raw GNSS measurements and accelerometers. Efficient utilization of these sensors and their data in CitSci projects can be promoted further.

- Individuals most of the time share the data they collect through various social media environments such as Facebook, Twitter, Forums, Trip and sightseeing blogs. This unconsciously shared data may include highly valuable information for managing emergency situations, better decision making and scientific experimentation. However, the extraction of such information, especially location of geographic information, from such a heap requires development of advanced data crawlers that may consume available metadata, apply artificial intelligence (AI) tools such as natural language processing (NLP), knowledge engineering, social network analysis, classification and sorting. This may be considered as the next generation of search engines, which are intelligent enough to decide whether a piece of information fits a specific purpose. Even after a successful searching and sorting of such a dataset is achieved, extraction and transformation of usable information from the dataset requires a definition of quality metrics and also development of software tools.

- On the other hand, when guided by higher level objectives, volunteered collection of such information with predefined quality metrics, data model and user interface is possible. There are various success stories for the VGI such as OpenStreetmap, eBird and WikiMapia, just to name a few. Although there are important standardization efforts mostly by Open Geospatial Consortium (OGC) to increase the interoperability of geographic information, the applications of these standards for VGI collection, storage, search and retrieval are still important issues.

- In order to cultivate multi-disciplinary research on VGI, tools and techniques are needed to simplify the merge of observations collected by different volunteer groups. OGC Semantic Sensor Network Ontology and Sensor Web Enablement related standards for example may provide the necessary common language for crawling, collecting, storing, searching and integrating sensor data from different studies. In this context, advanced software tools such as mobile applications that collect location information, photos and sensor data from cellular phones, gateways for cheap Internet of Things (IoT) sensors, sensor databases and services for extraction, transformation, load and analysis of sensor data.

- There is a need to make use of existing repositories of CitSci and VGI projects for developing AI, ML and deep learning (DL) based innovative solutions for object identification with faster retrieval on near real time basis. This would enable the utilization of the voluminous data in a more meaningful and lucid manner.

- Research on re-usable/configurable software development frameworks that rely on the abovementioned standards may ease the establishment of SDIs for VGI. In addition, these frameworks may also overcome the common problems associated with data quality, privacy and abuse and also bi-directional feedback. With such advanced tooling and contribution from volunteers, we may get closer to better understanding of our local neighborhood as well as global events.

Author Contributions: Conceptualization, validation, formal analysis, writing-original draft preparation, writing - review and editing, Sultan Kocaman, Sameer Saran, Murat Durmaz, Senthil Kumar. All authors have read and agreed to the published version of the manuscript.

Conflicts of Interest: The authors declare no conflict of interest. 


\section{References}

1. Singh, P.; Saran, S.; Kocaman, S. Role of Maximum Entropy and Citizen Science to Study Habitat Suitability of Jacobin Cuckoo in Different Climate Change Scenarios. ISPRS Int. J. Geo-Inf. 2021, 10, 463. [CrossRef]

2. Séférian, R.; Nabat, P.; Michou, M.; Saint-Martin, D.; Voldoire, A.; Colin, J.; Decharme, B.; Delire, C.; Berthet, S.; Chevallier, M.; et al. Evaluation of CNRM Earth System Model, CNRM-ESM2-1: Role of Earth System Processes in Present-Day and Future Climate. J. Adv. Model. Earth Syst. 2019, 11, 4182-4227. [CrossRef]

3. Wheeler, Q.D. What if GBIF? Bioscience 2004, 54, 718. [CrossRef]

4. Zhang, G. Spatial and Temporal Patterns in Volunteer Data Contribution Activities: A Case Study of eBird. ISPRS Int. J. Geo-Inf. 2020, 9, 597. [CrossRef]

5. Samulowska, M.; Chmielewski, S.; Raczko, E.; Lupa, M.; Myszkowska, D.; Zagajewski, B. Crowdsourcing without Data Bias: Building a Quality Assurance System for Air Pollution Symptom Mapping. ISPRS Int. J. Geo-Inf. 2021, 10, 46. [CrossRef]

6. Gulnerman, A.G.; Karaman, H.; Pekaslan, D.; Bilgi, S. Citizens' Spatial Footprint on Twitter-Anomaly, Trend and Bias Investigation in Istanbul. ISPRS Int. J. Geo-Inf. 2020, 9, 222. [CrossRef]

7. Gray, A.; Robertson, C.; Feick, R. CWDAT-An Open-Source Tool for the Visualization and Analysis of Community-Generated Water Quality Data. ISPRS Int. J. Geo-Inf. 2021, 10, 207. [CrossRef]

8. Yalcin, I.; Kocaman, S.; Gokceoglu, C. A CitSci Approach for Rapid Earthquake Intensity Mapping: A Case Study from Istanbul (Turkey). ISPRS Int. J. Geo-Inf. 2020, 9, 266. [CrossRef]

9. Vahidnia, M.H.; Vahidi, H. Open Community-Based Crowdsourcing Geoportal for Earth Observation Products: A Model Design and Prototype Implementation. ISPRS Int. J. Geo-Inf. 2021, 10, 24. [CrossRef]

10. Perdana, A.P.; Ostermann, F.O. Eliciting Knowledge on Technical and Legal Aspects of Participatory Toponym Handling. ISPRS Int. J. Geo-Inf. 2019, 8, 500. [CrossRef] 